\title{
Enjoying the Doubtful On Transformative Suspensions in Pragmatist Aesthetics
}

\section{Heidi Salaverría}

\section{CpenEdition}

\section{Journals}

Electronic version

URL: http://journals.openedition.org/ejpap/791

DOI: 10.4000/ejpap.791

ISSN: 2036-4091

\section{Publisher}

Associazione Pragma

\section{Electronic reference}

Heidi Salaverría, "Enjoying the Doubtful On Transformative Suspensions in Pragmatist Aesthetics », European Journal of Pragmatism and American Philosophy [Online], IV - 1 | 2012, Online since 23 July 2012, connection on 19 April 2019. URL : http://journals.openedition.org/ejpap/791 ; DOI : 10.4000/ ejpap.791

This text was automatically generated on 19 April 2019.

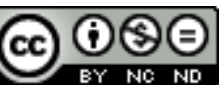

Author retains copyright and grants the European Journal of Pragmatism and American Philosophy right of first publication with the work simultaneously licensed under a Creative Commons AttributionNonCommercial-NoDerivatives 4.0 International License. 


\title{
Enjoying the Doubtful on Transformative Suspensions in Pragmatist Aesthetics
}

\author{
Heidi Salaverría
}

1 Richard Shusterman's pragmatism is an important voice in the pluralist choir of pragmatist philosophers and has crucially contributed to refine some of the most important pragmatist concerns, particularly those of Dewey. While he, like Dewey, criticizes the compartmentalization of the art-sphere and shows in detail the entanglement of the aesthetic and the ordinary, adopting and further developing his critical insights, Shusterman also detects some flaws in Dewey's vision. Rather "than pursuing Dewey's totalizing definitional quest" in dealing with aesthetic experience, he instead aims, "in the spirit of piecemeal pragmatist labor, to make a more specific case for widening art's borders to forms of popular culture and to the ethical art of fashioning one's life."1

2 But Shusterman also radicalized and broadened the pragmatist method or way of thinking, legitimizing a closer interaction of philosophy and the everyday (than Dewey allowed for), of which popular culture forms an integral part. Applying this approach to his own work, Shusterman has been the first philosopher to explore and appreciate philosophically the world of hip hop, not only by familiarizing himself with its culture and making its culture recognizable for an academic audience through his publications, but by arguing for its philosophical and aesthetic significance and legitimacy, and by showing how its culture challenges some flaws of academic philosophy, offering intriguing alternatives. ${ }^{2}$

3 Although generally benevolent in his discussions of philosophical positions, Shusterman for a long time has been surprisingly critical towards the aesthetic theory of Kant. This is partly understandable, as Kant's philosophy viewed as a system is in fact incompatible with pragmatism, and there are good reasons to reject some of his premises and limitations. ${ }^{3}$ Nevertheless there are some aspects in Shusterman's thinking which come 
quite close to Kantian ideas (and they already have - in some subcutaneous ways influenced pragmatist aesthetics via Emerson and Peirce). I believe that a careful connection could be beneficial and enriching both for Kantian and for pragmatist aesthetics. Shusterman himself writes in a recent article that he had "all too readily followed James (and Dewey) in being hypercritical of Kant, though my own pragmatist aesthetics shares with him (much more than with Hegel) an emphasis on pleasure, perception, and the experiential particularity of aesthetic reactions that cannot be reduced to the conceptual." 4

4 So in what follows, my paper explores some of the familiarities and tensions between their reflections on pleasure and on the particularity of aesthetic experience, thereby arguing that the transformatory element in aesthetic pleasure is doubt.

Why is it so crucial to underline the positive aesthetic experience of pleasure instead of concentrating on the critical examination of negative experiences (and their opposition and prevention through political philosophy and action) like pain, humiliation, and alienation, which dominate contemporary philosophical debates on feelings, as Shusterman rightly criticizes? Not only do late capitalist societies continue to reproduce the fatal and violent split between mind and body (besides innumerable other dualisms, e.g. subject/object, self/world, male/female, art/life, thought/feeling) and the corresponding depreciation of the somatic in contrast to the mental and linguistic, this split moreover resonates in the hierarchical dualism between popular and high culture, and this hierarchy in turn reverberates in those philosophical discourses which continue to neglect the somatic, and particularly the positive somatic and aesthetic experiences, a problem that "might be termed a radical anaestheticization of aesthetics" (PL: 31). Instead of taking a critical stance towards body-hostile tendencies in society (of which the medially inculcated fanaticism for violently standardized body-images and the equally standardized sensationalism of emotions, which are being confounded with pleasure, represent nothing more than the other Janus-faced side), contemporary philosophy tends to exacerbate the problem. Shusterman's insistence on pleasure should be understood as a critical response to the tendency to disdain pleasure and hence a part of ourselves (PA: 170).

6 A lot of misunderstanding regarding Shusterman's philosophical reevaluation of aesthetic pleasure can be attributed to a lack of understanding its essential and indispensable transformatory power (PA: 58, 59, 145). The problem, e.g., of many (post-)structuralist theories is that they tend to describe the subject in terms of an irreducible deficiency. The tendency towards an ever evanescent, and always somehow violently subjected subject not only reflects and partly reproduces the societal violence of the mind-body dualism. It also makes the problem of embodied agency seem increasingly unsolvable, other than to be content (in a very sad way) with the anonymous iterations and ruptures the unpredictability of discourses and the mishaps of speech-acts might offer as only source for renewal and change. Even more so, because these ruptures will always, at least partly, reproduce the implicit or explicit violence of its subjection, whereas unconstrained aesthetic pleasure involves the option of temporarily freeing the self from (at least some) boundaries by getting to know the new. And it is not only the fullness of unconstrained pleasure, but also the surplus of this experience, which Shusterman notes. "That aesthetic experience extends beyond the historically established practice of art should be obvious" (PA: 47). One of the reasons why he advocates popular culture is a consequence of this problem, as the experience of aesthetic pleasure hasn't been 
suppressed on such a scale in popular culture as in the so-called high art and its correspondingly expected aesthetic attitude. Furthermore this one-sided aesthetic attitude is inseparable from social hierarchies, in which - as Bourdieu has powerfully demonstrated - distinguished taste is instrumentalized to reinforce social classes, more perfidiously so, as the aesthetic, allegedly authentic and free judgment serves for social positioning. But neither does this entail a determination through social classes nor the nonexistence of valid aesthetic judgments or experiences altogether. The cultivation of rather intellectual aesthetic works, labeled as high art, and their reception is not per se problematic, but it is because of its implications: the exclusions, and the consolidation of those exclusions of social classes and of parts of our own self.

7 It would be trivial to make pleasure a philosophical key concept, if the point was to merely compensate for its negligence in our societies (without touching the societal structures which produced the problem in the first place). The significance of the recognition of aesthetic pleasure lies instead in its transformatory power. And this power can be best activated, in my view, when it is not separated from understanding, as Peirce famously wrote, describing the creative state of musement, as an "open conversation with yourself, [...] however, not a conversation in words alone." ${ }^{5}$ In this I see a strong connection between Kantian and pragmatist aesthetics, although Kant needs a pragmatist correction of his formalistic and body-hostile tendencies, whereas pragmatism could benefit from a stronger focus on the formation of a critical standpoint through aesthetic pleasure and aesthetic judgment. In his latest book on Somaesthetics, the discipline he has been unfolding in the last decade, Shusterman proposes that we should rely on our feelings and habits "until they prove problematic in experience." ${ }^{6}$ But it seems to me, that aesthetic pleasure (which, as I have learned from Shusterman, always is somehow somaesthetic) has more to offer: it not only opens the horizon to a more refined attention toward the somatic processes of our body, but also opens the horizon to a more refined attention on our own problematic positioning in the world. It is important temporarily to enjoy the problematic in an unconstrained way. Otherwise (soma)esthetic pleasure runs the danger of promising on the one hand "the richest and deepest palate of experiential fulfillments because it can draw on the profusion of cosmic resources, including an uplifting sense of cosmic unity," while being on the other hand subordinated to the fact "that habits must engage and assimilate the environments in which they function, particularly those environmental elements that support or enable their functioning." Shusterman's analysis at times contains, in my understanding, a somehow not quite connected opposition between the ideas of a cosmic somaesthetic experience, in which Emerson resonates, versus a functionalistic scientific vocabulary. The insistence on (som)aesthetic pleasure would run the danger, then, to be misunderstood as compensatory to our functioning instead of being transformatory, including the questioning of what is being conceived nowadays as functional, but might turn out to be problematic.

But how does pleasure mobilize transformations or serve as a compass in the process of transformation? In his essay The End of Aesthetic Experience, Shusterman proposes an interesting thought experiment to elucidate the indispensability of pleasure: imagine two visually identical viewers who offer identical interpretations of an artwork. One is human, the other one a cyborg, one is thrilled, the other one is not, for he only processes data in a way programmers told him to. The cyborg is capable of producing an interpretation of the given artwork, based on the information stored up in his software and the algorithms that process and combine them. But we "would surely say here," 
Shusterman concludes, "that the cyborg, in an important sense, doesn't really understand these works. He doesn't, in a big way, get to the point of such art, [...] he does not really grasp what art is all about" (PL: 30,31). Now, the cyborg does not lack one particular feature or capacity, which could in principle be installed, e.g., by adding a program that makes him express the required kind of pleasure. The cyborg does not grasp what art is altogether, because he does not grasp what pleasure is all about. To experience aesthetic pleasure in a big way means, in my view, that the human self, in Kantian terms, "feels itself," whereas the cyborg is unable to do so. ${ }^{8}$ It means for the self, furthermore, to "feel itself" in a double sense: the self notices how it feels when facing an aesthetic situation (whether this is constituted by a work of art, nature, or an aesthetic experience in the wider sense of pragmatism, is a question I prefer to leave open), e.g. being excited, calmed, delighted, etc. But the self simultaneously focuses its attention on itself: its subjectivity becomes the object of its attention. ${ }^{9}$ Corresponding to this double sense of "feeling itself," a double movement takes place: the self might feel immediately attracted or unsettled by an aesthetic situation. But in contrast to other daily situations, which might pass by automatically, driven by established habits, the aesthetic situation lingers on, because it is pleasurable in a peculiar way. "We linger," Kant writes, "over the consideration of the beautiful because this consideration strengthens and reproduces itself" (CPW: 107).

This lingering consists for Kant in the free play of the faculties (of imagination and understanding), and pleasure is a result of that free play (CPW: §9, 103). Kant at this point distinguishes between pleasure and the agreeable, which denotes the sensual, rather passive enjoyment without reflection. Whereas the agreeable is driven by interest, pleasure is disinterested. One of the strongest objections to Kant's aesthetics articulated by Dewey and Shusterman is that the attitude of disinterestedness is not only artificial, but an attitude, which can only be taken on by the socio-economically and culturally privileged (PA: 263, fn. 11). It seems problematic, however, to establish a strict dichotomy by excluding the disinterestedness altogether in favor of a pure interestedness, and in fact Shusterman elsewhere insists that the means-end-dichotomy needs to be overcome by a view that art "is thus at once instrumentally valuable and a satisfying end in itself." The interest in aesthetic pleasure involves "enhancing our immediate experience which invigorates and vitalizes us, thus aiding our achievement of whatever further ends we pursue" (PA: 9). There is, contra Kant, no reason for excluding the interest-led agreeable, but the aesthetic shouldn't be reduced to it. This would be a problem, because a reduction of a situation to the agreeable would stop the lingering too soon, and that would be a problematic constraint, if it could be undergone in a transformative way. The attractions of a fashionable pair of sneakers or a fashionable production of a Wagnerian opera have their aesthetic worth, as long as they include an ongoing lingering. Other than that they are merely agreeable commodities. The decision whether something is considered as part of an 'agreeable' and often violently inculcated mass (or deceitful high) culture, or of a potentially critical and pleasurable popular (or unpopular) culture amounts, in my view, to the question of how much lingering takes place. When we agree with Bourdieu in that the seemingly disinterested aesthetic judgment actually represents a positioning in a social class, then the disinterest conceals a very strong interest, namely one of being recognized as part of a distinguished class by excluding others, in which case the alleged pleasure of 'high art' would turn out to be nothing more than agreeable, when reduced to that interest. On the other hand popular culture can (as well as any other aesthetic 
situation, depending on the given context) mobilize a lingering, which might transform the self.

It seems more fruitful to me, rather than to scrutinize exegetically Kant's transcendental system at this point, to adapt his ideas pragmatically, even to sample and recombine his valuable insights for the problem in question, namely the question of the transformatory power of pleasure. For Kant, pleasurable lingering is crucial, because it allows an unconstrained aesthetic (or reflective) judgment to take place. In opposition to determining judgments, which subsume something particular under a general concept, the aesthetic judgment has no rule. As Kant points out, it differs from practical or theoretical judgments in that it always judges a singular situation. While in a scientific experiment an example is given, which is in principle exchangeable, in the aesthetic situation it is not. ${ }^{10}$ It is, in Kant's words, exemplary (CPJ: $\left.§ 18,121\right)$. The self, moreover, does not have a clear idea about the character of its exemplary situation: it needs to find out what the situation is about, including the open question, who itself is in this specific singular situation and, thus, who it could be in the future. The self tries to situate itself in relation to the aesthetic situation. "Beautiful things," Kant writes, "indicate that human beings find the world to be a place suited to them."11 This important aspect of pleasure includes the capacity of not only feeling the pleasure in reaching out for the new, but of feeling compatible with the social and natural world. But this does not mean that the self needs to adapt to the social and natural world and to succumb to its criteria. It should instead be interpreted as actively imagining and anticipating a situation, in which the self could feel at home. ${ }^{12}$ So, paradoxically, to feel itself, the self needs not only to free itself from constraints on itself, but, to a certain extent, needs to be freed of its constrained self, as the restrictions which limit its possibilities aren't something external it could take off like a hat. Unconstrained aesthetic pleasure can temporarily suspend the subjected self, which in turn implies, as Cavell once put it, to open to "our beyond." ${ }^{13}$ This is why Kant (echoing in Cavell through Emerson) supposed that in aesthetic pleasure others are implied: we wish to share our aesthetic pleasure with others because we already appeal to them virtually in search for new criteria, for a different, a modified self. Translated into pragmatist vocabulary: suspending the self temporarily means opening up to those vaguely conceived but forgotten or repressed alternative options of thinking, feeling and acting (with James: to the fringes of the self), ${ }^{14}$ left out in habitual action. Aesthetic pleasure temporarily opens up an unconstrained space in which the suspended self reaches out to alternatives, in Cavell's words, to "open to the further self, in oneself and in others, which means holding oneself in knowledge of the need for change." ${ }^{15}$ The problem with Cavell is, as Shusterman convincingly diagnoses, that his perfectionism tends to reproduce a depreciative posture towards the body and its pleasures, thereby confining his perfectionist striving to a rigorously self-critical regimen of reading and writing, and thereby constraining the possible unconstrained lingering which is so important. Only through unconstrained loosening of the borders of habitual thinking and feeling, the fringes of the intelligible are being mobilized and the "internalized practice [which] is always already marked by conflict and points in different directions" (PA: 60) can be perceived in a different light: the formerly unnoticed (or, due to conflicts, the seemingly incompatible) can be noticed (or be seen in a new connection) and, by this, help to overcome not only entrenched habits, but as well - in the long run - to transform the formerly taken for granted common sense. To appeal to others in aesthetic pleasure means to appeal to a partly utopian sensus communis. ${ }^{16}$ 
11 The lingering makes the formerly unknown or the new accessible. That, "with which the imagination can play in an unstudied and purposive way is always new to us, and we are never tired of looking at it" (CPW: 126). In the process of searching the self lets its thinking go loose, the status as a self with a firm identity is temporarily being suspended, in suspense. The aim is to restructure the known habits and vocabularies facing something not yet understood, which mobilizes a whole variety of imaginings in a pleasurable manner. The concrete instrumental interests of the self are transitorily suspended in favor of a different kind of interest. This disinterested "interest" or urge does not have to do primarily with concretely desired objects, but with a repositioning of the self through the aesthetic exploratory movement. It is rather comparable to the urge to solve a riddle (and not to solve it to impress others, but just to solve it), only that the riddle is the self. Another way to say it would be that the self finds itself in a situation of enjoying the doubtful, mainly the doubtful of itself. A pleasurable self-doubt is mobilized in the search for new criteria in a dubitable aesthetic situation.

Unconstrained pleasurable doubting involves a resolution of a somehow unresolved situation of the self: do I like what I see (hear, feel, taste)? If the answer were clear, no aesthetic entanglement would take place. But in contrast to many postmodern or poststructuralist accounts of the subject, it is not the lack or deficiency, which fuels the exploratory movement of searching for new ways (of feeling, thinking, acting), it is on the contrary the abundance of not yet disentangled associations and feelings, which move the self. This kind of abundance Kant has in mind resembles the "spilling over" Shusterman sees in connection with aesthetic experience (PA: 10). And to feel pleasure in the face of something yet unknown, it seems to me, is exactly what Dewey had in mind when he pointed out the possibility of "enjoying the doubtful."17

This unconstrained enjoyment of the doubtful implies a positive rivalry between imagination and understanding, as the former continues to produce associations, diving deeper into the situation, whereas the latter seeks to grasp the yet uncomprehended, to make the unutterable utterable. This lingering on the verge of the conceptual, as there is something new, "spilling over" the familiar vocabularies and habits, is another aspect pragmatism and Kant have in common. But pragmatism tends to discern the aesthetic experience from the process of doubting, which is mostly being associated with negative feelings of tension. In my view, however, aesthetic experience implies a positive tension between habitual pleasures and doubts. This idea of pleasurable doubts even resonates in James' famous definition of truth, which - taking into account the pragmatist dismissal of the classical compartmentalization between the good, the true, and the beautiful, or, with Shusterman, that "the aesthetic is continuous with the practical and cognitive and that all these different factors or interests can be integrated in the unity of experience" 18 - is applicable to the process just described: "New truth is always a go-between, a smootherover of transitions. It marries old opinion to new fact so as ever to show a minimum of jolt, a maximum of continuity. [...] The reason why we call things true is the reason why they are true, for 'to be true' means only to perform this marriage function." ${ }^{19}$ The free play of imagination and understanding could then be translated pragmatically into the free play of the old (concepts of understanding, old beliefs, and habits) and the new (imaginations, somatic experiences, and associations). The metaphor of marriage charmingly suggests an erotic entanglement of 'old' and 'new.' Accordingly, 'Old' and 'New' have fallen in love with each other, thus establishing a positive tension (as in the tension between understanding and imagination), but this tension implies doubts with 
respect to the uncertain future and the question over how the matter will play out. The capacity for transformation or creativity in a strong sense requires doubting. ${ }^{20}$

Moreover, in the aesthetic experience and judgment activity is included, as Kant and Dewey advocate. ${ }^{21}$ But this kind of activity is, as Shusterman underlines, not fully controllable by the self. The "reduction of appreciation to self-assertive critical production denies us the enrichment and pleasure gained from submitting ourselves to art's alterity and seductive power" (PA: 54). It is rather a process, which in a pleasurable way puts into question what was taken for granted before. Rorty had something similar in mind when, talking of creativity, he wrote of "flirtations with the meaningless," quoting Frye. ${ }^{22}$ Rorty, however, limited creative self-doubts to the invention of new vocabularies, a limitation to the lingustic, for which, as Shusterman has convincingly shown, there exists no good reason, because, if "we can emancipate and transform the self through new language, we can also perhaps liberate and transfigure it through new bodily practices" (PA: 260).

One could object that the unconstrained lingering of pleasure doesn't provide us either with an answer to the question of embodied agency nor to the question of how to counteract societal and individual constraints, violence and cruelty. "We cannot be reminded too often," Shusterman writes, "of the aesthetically refined Nazi officers who would weep at Beethoven to express their human emotions while inhumanly orchestrating the wholesale slaughter of innocent children" (PA: 155). I absolutely agree. In the case of the aesthetically refined Nazi a particularly sick version of 'aesthetic experience' is at work, in which not even the slightest self-doubt is being heard. But - as Shusterman rightly underlines - this kind of immoral compartmentalization repeats itself constantly in less extreme forms in our everyday behavior.

This is why it is so important to emphasize the doubtful, particularly the self-doubts. It is crucial for the embodied agency of the self as doubting implies the ambiguity of unsettling and resettling the self and its habits. Doubts do not only unsettle the self, signalizing an error committed by the self or experienced in the environment (e.g. the structures of society). They also resettle the self by signalizing am emerging new contour of the own positioning. Some part of the self, allegedly known, is being weakened, and simultaneously some part of the self, yet unknown, is being encouraged through the enjoyment of the uncertain. In contrast to poststructuralist accounts on the subject driven by lack, aesthetic doubts enable the self to experience the 'lack' of temporarily being uncertain in an unconstrained way, inviting a diving into unknown terrains, which might bring up something helpful. Doubting urges the self to position, its singularity being at stake by connecting to something new, because the "creative ameliorative reshaping of life is an endless task," in which "each person must reckon with her own color and thickness of lens." ${ }^{23}$ Only if we cultivate our individual radar for the doubtful in us and in society, if we train ourselves somaesthetically to endure and even to enjoy the tensions of the uncertain instead of impatiently shrugging them off can we contribute to a new partage du sensible, as Rancière calls it, by transforming the rigid limitations of our perception that can do so much harm..$^{24}$ 


\section{NOTES}

1. R. Shusterman, (1992), Pragmatist Aesthetics. Living Beauty, Rethinking Art, Cambridge, Mass., Blackwell, (hereafter cited as PA), 59.

2. See PA, chapters 7 and 8; see R. Shusterman, (1997), Practicing Philosophy. Pragmatism and the Philosophical Life, New York, Routledge 1997 (hereafter cited as PP), chapter 5; see R. Shusterman, (2000), Performing Life. Aesthetic Alternatives for the Ends of Art, London, Cornell and Ithaka (hereafter cited as PL), chapter 3.

3. See R. Shusterman, (1993), On the Scandal of Taste: Social Privilege as Nature in the Aesthetic Theories of Hume and Kant, in P. Mattick (ed.), Eighteenth Century Aesthetics and the Reconstruction of Art, Cambridge University Press, 96-119.

4. R. Shusterman, (2011), "The Pragmatist Aesthetics of William James," British Journal of Aesthetics , 51 (4), 350, Fn. 11.

5. C. S. Peirce, A Neglected Argument for the Reality of God (CP 6.460-461). See also R. Shusterman, (2009), "Somaesthetics and Charles S. Peirce," Journal of Speculative Philosophy, 23 (1), 12. For a discussion on the implications of doubts, musement, and abduction for creativity in Peirce, see H. Salaverría, (2007), Spielräume des Selbst. Pragmatismus und kreatives Handeln, Berlin, Akademie, 70-83; 137-49.

6. R. Shusterman, (2008), Body Consciousness. A Philosophy of Mindfulness and Somaesthetics, Cambridge, Cambridge University Press, 212.

7. R. Shusterman, Body Consciousness, cit., 214; 216.

8. I. Kant, (2000), The Critique of the Power of Judgment, The Cambridge Edition of the Works of Immanuel Kant, ed. Paul Guyer, transl. by P. Guyer \& Eric Matthews, New York, Cambridge University Press, (hereafter cited as CPW), § 1, 5: 204.

9. The question of somaesthetic attention is treated in detail in Shusterman's Body Consciousness, particularly in chapt. 5 .

10. In Kuhn's vocabulary: of the normal science, not of the revolutionary science. Of course, Kant's compartmentalization of practical, theoretical, and aesthetic judgments is highly contentious. There is no room to discuss the problem in this essay, but suffice it to note that the development of the new in every area implies an aesthetic dimension, as, e.g., Peirce's analysis of the abduction shows.

11. Immanuel Kant, XVI, 127, no. 1820a, in H. Arendt, (1992), Lectures on Kant's Political Philosophy, ed. by Ronald Beiner, Chicago, Chicago University Press, 30, transl. modified.

12. For a political interpretation of this quote see L. Zerilli, (2005), “'We feel our freedom.' Imagination and Judgment in the thought of Hannah Arendt," Political Theory, 33 (2), 158-88.

13. S. Cavell, (1990), Conditions Handsome and Unhandsome. The Constitution of Emersonian Perfectionism, Chicago-London, Chicago University Press, 58. See Shusterman's discussion of Cavell's perfectionism in PP: 99-110.

14. To which Shusterman refers in his "The Pragmatist Aesthetics of William James," cit., 359.

15. S. Cavell, Conditions Handsome and Unhandsome, cit., 125; See also PP: 103.

16. I develop a pragmatist interpretation of Kant's sensus communis (in conjunction with and comparison to pragmatist, critical common sense) in H. Salaverría, spielräume des Selbst. Pragmatismus und Kreatives Handeln, cit., 227-66.

17. Dewey J., (1930), The Quest for Certainty. A Study of the Relation of Knowledge and Action, The Later Works of J. Dewey, 1925-1953, vol. 4 (LW 4), ed. by J. A. Boydston, Southern Illinois University Press, Carbondale and Edwardsville, 182. 
18. R. Shusterman, The Pragmatist Aesthetics of William James, cit., 358.

19. W. James, (1981), Pragmatism. A New Name For Some Old Ways of Thinking, ed., with an introduction by Bruce Kuklick, Indianapolis-Cambridge, Hackett, 31; 33.

20. See also Dewey J., (1934), Art as Experience, The Later Works of J. Dewey, 1925-1953, vol. 10 (LW 10), ed. by J. A. Boydston, Southern Illinois University Press, Carbondale and Edwardsville 1987, 263.

21. For a detailed exploration of Dewey's theory of judgment, also taking into consideration Cavell, see R. Frega, (2006), Pensée, Experience, Pratique. Essai Sur la Théorie du Jugement de John Dewey, Paris, L'Harmatton, $279 f$.

22. M. Frye, (1983), Politics of Reality, New York, Trumansburg, 154, quoted in R. Rorty, (1998), Feminism and Pragmatism, in R. Rorty, Truth in Progress. Philosophical Papers III, Cambridge University Press, 217.

23. R. Shusterman, (1999), "Emerson's Pragmatist Aesthetics," Revue Internationale de Philosophie 1, 207, 94; PL: 217. For a detailed account on pragmatist doubts and its aesthetic implications see H. Salaverría, Spielräume des Selbst, cit., 49-131.

24. For a discussion on the perceptive limits of recognizability, see H. Salaverría, (2011), Anerkennbarkeit. Butler, Levinas, Rancière, in A. Hetzel (ed.), Alterität und Anerkennung, Baden Baden, Nomos, 35-55.

\section{AUTHOR}

\section{HEIDI SALAVERRÍA}

Heidi[at]salaverria.de 